\title{
REACTION OF MOLECULAR OXYGEN WITH CHROMIUM, COBALT AND NICKEL METALLOCENES IN DIMETHYLSULFOXIDE. CORRELATION BETWEEN ITS POLAROGRAPHIC AND BOND LENGTHS PARAMETERS
}

\author{
WALTER ZAMUDIO ${ }^{1 *}$, NUBIA DUARTE ${ }^{l}$, ANA MARÍA GARCÍA ${ }^{l}$ AND MARCELO CAMPOS VALLETTE ${ }^{2}$ \\ ${ }^{1}$ Chemical Engineering Dept., Faculty of Physical and Mathematical Sciences, Universidad de Chile. \\ ${ }^{2}$ Chemistry Dept., Faculty of Sciences, Universidad de Chile. \\ POBox653, Santiago, Chile.facien05@uchile.cl
}

\begin{abstract}
The reaction of oxidation with molecular oxygen in dimethyl sulfoxide is of order one in the metallocenes; the specific reaction constant decreases from nickel, chromium to cobalt. A reaction mechanism is proposed. The values of the polarographic constants and the bond lengths vary linearly with respect to the increase of the specific reaction constant but with opposite slopes.
\end{abstract}

Keywords: metallocenes, polarography, oxidation, reactivity.

\section{INTRODUCTION}

Phenanthroline and its derivatives by the substitution of its hydrogen in position 5 by groups such as $\mathrm{Cl}, \mathrm{CH}_{3}, 5,6$-dimethyl allowed the synthesis of cuprous complexes. On this basis it has been possible to study the reaction rate with molecular oxygen in an organic solvent and to correlate it with the property of the base, with the formation constants of the cuprous complexes in dimethylsulfoxide and/or with the vibration frequency of the $\mathrm{Cu}-\mathrm{N}$ bond ${ }^{1,2}$. But in this system it is not possible to change the central ion by another without changing other properties.

It is possible to isolate sandwich metal complexes from the cyclopentadiene radical $\mathrm{C}_{5} \mathrm{H}_{5},(\mathrm{Cp})$. Metallocenes $\left(\mathrm{MCp}_{2}\right)$, are well-known $\pi$ bonds complexes in organometallic chemistry. The ferrocene was the first metallocene synthesized in 1951. It is a diamagnetic compound whose chemical stability is explained because it has an electron structure of 18 electrons in its outer layer. This number of electrons is calculated considering the external electrons of the iron atom $\mathrm{d}^{6} \mathrm{~s}^{2}$, and the ten electrons of the two groups of cyclopentadiene. However, it is possible to oxidize it in strongly acidic medium ${ }^{3}$ due to the protonated form of the metallocene $\mathrm{Fe}\left(\mathrm{C}_{2} \mathrm{H}_{5}\right)_{2} \mathrm{H}^{+}$.

$\mathrm{Co}\left(\mathrm{C}_{5} \mathrm{H}_{5}\right)_{2}$ and $\mathrm{Ni}\left(\mathrm{C}_{5} \mathrm{H}_{5}\right)_{2}$ have the same sandwich structure as ferrocene but with 19 and 20 electrons in their outer layer, so they are chemically unstable; they have a magnetic dipole moment corresponding to an unpaired electron (1.83 $\mathrm{MB})$ and two unpaired electrons $(2.88 \mathrm{MB})$, respectively. $\mathrm{Cr}\left(\mathrm{C}_{5} \mathrm{H}_{5}\right)_{2}$ has a magnetic moment corresponding to two unpaired electrons and only 16 electrons in its outer layer ${ }^{4}\left(\mathrm{Cr}^{0}=\mathrm{d}^{5} \mathrm{~s}\right)$.

In order to contribute to the chemistry of metallocenes we have studied the reaction of molecular oxygen with chromium, cobalt and nickel metallocenes in dimethylsulfoxide and we have established a correlation between its polarographic and bond lengths parameters. These compounds were studied from the polarographic point of view. The potential $\mathrm{E}_{1 / 2}$ equal to $-0.67 \mathrm{~V}$, corresponds to the formation of $\mathrm{CrCp}_{2}{ }^{+}$via a reversible oxidation of one electron ${ }^{5}$; the $\mathrm{E}_{1 / 2}$ is $-0.08 \mathrm{~V}^{6}$ for $\mathrm{NiCp}_{2}{ }^{+}$and $-0.94 \mathrm{~V}^{7}$ for $\mathrm{CoCp}_{2}{ }^{+}$. It has been reported that cobaltocene is very sensitive to the action of oxygen in acid ${ }^{8}$ and still oxidizes the Fe and Co ions ${ }^{9}$. Nickelocene and cromocene have been oxidized chemically to the monocationic species ${ }^{10}, \mathrm{MCp}_{2}{ }^{+}$.

It has been reported ${ }^{11}$ that metallocene catalysts are "just a rumble on the tracks, but it's certainly a train that's coming." The plastics industry, by most accounts, is moving into an era based on a new generation of catalysts and entirely new polymeric materials. In this sense, various papers have been published in the present decade; for instance, Kaminsky cited ${ }^{12}$, "One of the most efficient and versatile ways to synthesize polyolefin nanocomposites is the in-situ polymerization of olefins in the presence of nano particles by metallocene catalysts".

\section{EXPERIMENTAL}

Dimethylsulfoxide was distilled in vacuum to obtain water content not higher than $2 \times 10^{-3} \mathrm{M}$. The oxygen concentration in the reaction was controlled using a Beckman oxygen analyzer provided with a glass electrode and one inscriptor. The concentration of the metallocenes was at least 10 times higher than that of oxygen. Under these conditions the concentration of the metallocene remains constant during the reaction. The reactions were studied at $23^{\circ} \mathrm{C}$. Metallocenes of $\mathrm{Cr}$, $\mathrm{Co}$ and $\mathrm{Ni}$ were provided by Aldrich.

\section{RESULTS AND DISCUSSION}

The molecular oxygen oxidation kinetics of $\mathrm{CoCp}_{2}, \mathrm{NiCp}_{2}$ and $\mathrm{CrCp}_{2}$ in dimethylsulfoxide follows a first-order kinetic law with respect to the concentration of these metallocenes:

$$
\begin{aligned}
& \mathrm{R}=\mathrm{K}_{1}\left(\mathrm{MCp}_{2}\right)\left(\mathrm{O}_{2}\right) \\
& \mathrm{k}_{\mathrm{o}}=\mathrm{k}_{1}\left(\mathrm{MCp}_{2}\right)
\end{aligned}
$$

This is according to the experimental data obtained at $23^{\circ} \mathrm{C}$ and summarized in the Table.

Table. Kinetics of oxidation with $\mathrm{O}_{2}$ for $\mathrm{CoCp}_{2}, \mathrm{NiCp}_{2}$ and $\mathrm{CrCp}_{2}$ in dimethylsulfoxide. Experimental oxidation rate constants $\mathrm{k}_{0}\left(\mathrm{seg}^{-1}\right)$ at $23^{\circ} \mathrm{C}$.

\begin{tabular}{|c|c|c|c|c|c|}
\hline $\mathbf{C o}^{*}$ & $\mathbf{k}_{\mathbf{0}} * *$ & $\mathbf{C r}$ & $\mathbf{k}_{\mathbf{0}}$ & $\mathbf{N i}$ & $\mathbf{k}_{\mathbf{0}}$ \\
\hline 7.03 & 4.44 & 1.54 & 1.76 & 1.49 & 2.80 \\
\hline 4.60 & 1.28 & 3.08 & 3.37 & 2.97 & 10.35 \\
\hline 2.48 & 0.53 & 4.62 & 4.18 & 4.46 & 10.13 \\
\hline 9.10 & 8.50 & 6.16 & 8.83 & 5.94 & 13.30 \\
\hline 6.05 & 3.68 & 7.70 & 9.04 & 7.43 & 21.00 \\
\hline 3.03 & 0.78 & 9.24 & 12.13 & 8.92 & 21.73 \\
\hline 8.74 & 2.35 & 12.34 & 20.91 & 10.40 & 27.87 \\
\hline 5.83 & 0.85 & & & 12.00 & 37.30 \\
\hline 0.91 & 0.85 & & & & \\
\hline
\end{tabular}

$*$ Molar x $10^{-4}, * * \mathrm{k}_{0} \times 10^{-4}$ 
Regarding the concentration of the metallocenes it was possible to calculate the values of $\mathrm{k}_{0}=\mathrm{k}_{1}\left(\mathrm{MCp}_{2}\right)$.

$\mathrm{k}_{1}$ resulted to be 2.6, 1.3 and $0.56 \mathrm{M}^{-1} \mathrm{seg}^{-1}$ for $\mathrm{NiCp}_{2}, \mathrm{CrCp}_{2}$ and $\mathrm{CoCp}_{2}$, respectively. Ferrocene is not oxidized under the same experimental conditions.

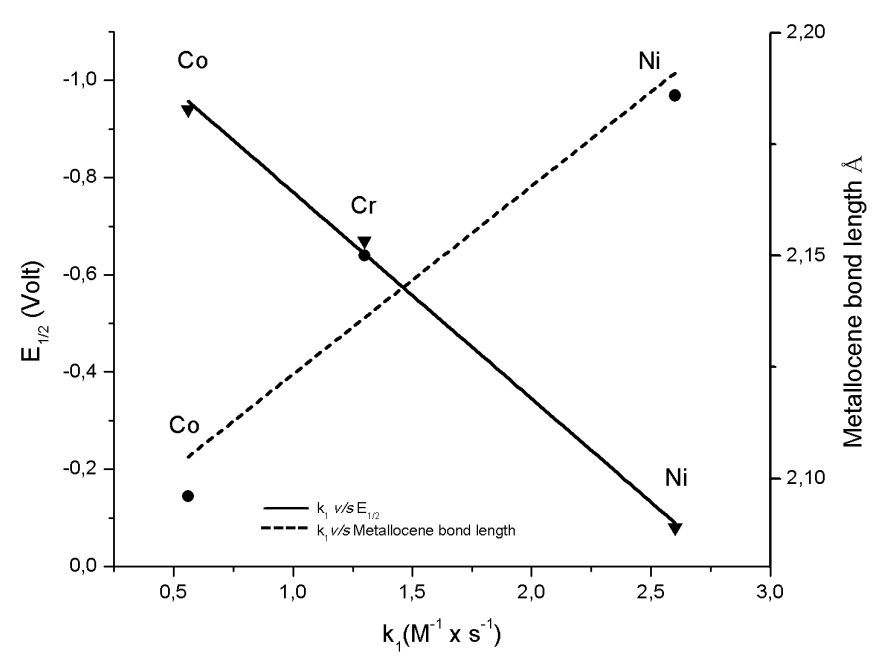

Figure. Polarographic and bond lengths parameters of $\mathrm{Co}, \mathrm{Cr}$ and $\mathrm{Ni}$ metallocenes.

The reaction mechanism proposed is:

$$
\begin{array}{ll}
\mathrm{MCp}_{2}+\mathrm{O}_{2} & \stackrel{\mathrm{K}_{3}}{\leftrightarrow} \mathrm{MCp}_{2} \cdot \mathrm{O}_{2} \quad \text { (Adduct) } \\
& \mathrm{k}_{4} \\
\mathrm{MCp}_{2} \mathrm{O}_{2} & \rightarrow \mathrm{MCp}_{2}+\mathrm{O}_{2}^{-}
\end{array}
$$

The $\mathrm{O}_{2}^{-}$would react with the solvent to possibly form dimethylsulfone, $\left(\mathrm{CH}_{3}\right)_{2} \mathrm{SO}_{2}$. The specific reaction constant $\mathrm{k}_{1}$ corresponds to $\mathrm{K}_{3}{ }^{\bullet}-\mathrm{k}_{4}$. The data obtained at this temperature suggest that the specific reaction rate follows the $\mathrm{CoCp}_{2}<\mathrm{CrCp}_{2}<\mathrm{NiCp}_{2}$ sequence because they have one, two and two unpaired electrons, respectively. Nickelocene and chromocene have a higher reaction rate since each adduct with oxygen has two unpaired electrons to react. Nickelocene has the higher reaction rate, which is a consequence of its higher bond length allowing the incorporation of the acceptor oxygen.

With the $\mathrm{k}_{1}\left(\mathrm{M}^{-1} \mathrm{seg}^{-1}\right)$ values obtained versus the polarographic values $\mathrm{E}_{1 / 2}$ (V) it is possible to infer that the lower oxidation potential of the $\mathrm{NiCp}_{2}$ involves a greater reactivity to oxygen. Cobaltocene displays the higher $\mathrm{E}_{1 / 2}$ value and the lower $\mathrm{k}_{1}$. By plotting $\mathrm{k}_{1}$ versus the bond lengths of the metallocenes, Co (2.096 $\AA), \mathrm{Cr}(2.15 \AA)$ and $\mathrm{Ni}(2,185 \AA){ }^{13}$, a straight line is obtained where the lower and upper limits correspond to cobaltocene and nickelocene, respectively; see Figure.

\section{CONCLUSIONS}

The reaction of oxidation with molecular oxygen in dimethyl sulfoxide is of order one in the metallocenes; the specific reaction constant decreases from nickel, chromium to cobalt. A straight line resulted when plotting the values of the polarographic constants and the reaction constants. The value of the rate constant increases linearly when increasing the bond length.

\section{REFERENCES}

1. J. Arce, E. Spodine, W. Zamudio. Inorg. Nucl. Chem., 18 (1976) 2029.

2. W. Zamudio, R. Barahona and M. Campos. Polyhedron., 17 (1998) 159.

3. Th. E. Witterwolf and A. Campbell. J. Organometallic Chem., 40 (1972) C29.

4. G. Wilkinson. J. Am. Chem. Soc., 76 (1954) 209.

5. J. D. L. Holloway and W. E. Geiger. Anal. Chem., 50 (1978) 1010.
6. G. Wilkinson. P. Pauson and F. Cotton. J. Am. Chem. Soc., 76 (1954) 1970.

7. W. E. Geiger. J. Am. Chem. Soc., 96 (1974) 2632.

8. J. Page and G. Wilkinson. J. Am. Chem. Soc., 74 (1952) 6149.

9. G. Wilkinson. J. lnorg. Nucl. Chem., 2 (1956) 95.

10. E. O. Fischer and R. Jira. Z. Naturförsch. B., 8 (1953) 217.

11. A. M. Thayer, Chem. Eng. News., 73 (1995) 15.

12. W. Kaminsky. Materials., 7 (2014) 1995.

13. "Infrared and Raman Spectra of inorganic and coordination compounds" Kasuo Nakamoto, John Wiley and sons. Inc. 605 Third Avenue., N.Y.1997. 